\title{
Outcome of Sofosbuvir containing Treatment Regimens in Egyptian Chronic Hepatitis C Patients with Thrombocytopenia
}

\author{
Sahar G Zaghloul ${ }^{1}$, Ashraf A Hammam², Fady M Wadea ${ }^{3}$, Mohamed R Saeed ${ }^{4}$ \\ Internal Medicine Department, Faculty of Medicine, Zagazig University, Zagazig, Egypt
}

\begin{abstract}
Introduction: chronic HCV patients with thrombocytopenia have difficulty in initiating or maintaining therapy with potential for progression of liver disease if treatment is postponed. Objectives: to evaluate impact of thrombocytopenia on the outcome of 2 sofosbuvir containing regimens used in Egypt for treatment of chronic hepatitis $C$ patients. Material and methods: a prospective cohort study included 260 chronic HCV patients stratified into 2 groups; group I included 60 patients with platelet count $\geq 150,000 / \mathrm{mm}^{3}$ as a disease control and group II (thrombocytopenia group) included 200 patients with platelet count ranged from 30,000- 149,000/mm 3 which was sub grouped according to severity of thrombocytopenia into $A$ and B. Patients were subjected to dual or triple therapy according to criteria for interferon illegibility or ineligibility recommended by national committee for chronic viral hepatitis (NCCVH), 2014. Results: sustained virological response and relapse in patients with thrombocytopenia didn't significantly differ from normal platelets patients and didn't differ significantly between thrombocytopenic patients received triple or dual therapy. Cirrhotic and advanced Child's score thrombocytopenic patients had significantly lower sustained virological response $(p=0.03 \& 0.001)$. Complications during and after termination of therapy didn't significantly differ from patients with normal platelets. Significant improvement of thrombocytopenia was achieved following the course of dual therapy. Conclusion: thrombocytopenia had no impact on decreasing sustained virological response or increasing relapse with these sofosbuvir regimens. Cirrhosis and advanced Child's score are significant factors in decreasing the rate of sustained response in these patients. Further studies are needed in patients with thrombocytopenia in the era of newly developed directly acting antiviral drugs especially in cirrhotic and treatment experienced.
\end{abstract}

Keywords: Blood platelets, hepatitis C chronic, interferon, liver cirrhosis, sofosbuvir.

\section{Introduction}

Up to $170-200$ million people (about $3 \%$ of the world population) have chronic HCV and about 2.4 million deaths occur each year. Recently reported that the average annual age-adjusted mortality rate due to hepatitis $\mathrm{C}$ was increased by 0.18 deaths per 100000 patients per year [1].

Egypt has the highest prevalence rate of HCV in the world and genotype 4 is the commonest type, particularly subtype 4a [2]. Studies show that $14.7 \%$ of the Egyptians carry HCV antibodies while $9.8 \%$ have active infection [3].

$\mathrm{HCV}$ prevalence in adults began to decline to $7 \%$ [4] following construction of 32 specialized centers for treatment of chronic HCV in Egypt with the aim of treatment of as much of Egyptian patients.

The main transmission route in Egypt was attributed to the prolonged use of parenteral anti- bilharzial therapy (tartar emetics) with the use of non-disposable glass syringes for more than 30 years [5].

HCV therapy has evolved over the past years. Initial therapies used interferon (IFN) monotherapy, this was followed by combination of a ribavirin and either PEG-IFN alfa-2a or PEG-IFN alfa-2b [6].

Sofosbuvir (SOF) is a new generation of directly acting antivirals (DAAs). It is a nucleotide analog that is a highly potent inhibitor of the NS5B polymerase in $\mathrm{HCV}$ [7] which increase the sustained virological response (SVR) rates with fewer adverse effects and shorter duration of treatment. SOF is used with or without PegIFN and/or ribavirin combination. In IFN eligible patients, the regimen duration is a 12-wk of PegIFN and ribavirin plus SOF but in IFN ineligible patients, a treatment for $24-w k$ with $\mathrm{SOF} /$ ribavirin is alternative [8].

Thrombocytopenia in HCV patients occurs due to the interaction of many factors [9]. The challenge in the treatment of chronic HCV patients with thrombocytopenia is the difficulty in initiating or maintaining therapy [10]. Delay of therapy due to thrombocytopenia can result in diminished SVR and potential for progression of liver disease; additional medications may also be needed during their treatment [11].

Our aim was to evaluate the impact of low platelet count on outcome of 2 sofosbuvir containing regimens used in Egypt during the period from October 2014 to October 2015 for treatment of chronic hepatitis $\mathrm{C}$ patients.

\section{Material and Methods}

This prospective cohort study included a total of 260 patients with chronic hepatitis $\mathrm{C}$ virus indicated for treatment according to inclusion and exclusion criteria. All patients were recruited from Gastroenterology and Hepatology unit outpatient clinic, Internal Medicine department, Faculty of Medicine, Zagazig University hospitals in collaboration with El-Ahrar specialized center, Zagazig, Egypt from October 2014 to October 2015. 


\section{International Journal of Science and Research (IJSR) \\ ISSN (Online): 2319-7064 \\ Index Copernicus Value (2015): 78.96 | Impact Factor (2015): 6.391}

The subjects were grouped into 2 groups:

1) Group I (non thrombocytopenic group): included 60 chronic HCV patients with platelets count $\geq$ $150,000 / \mathrm{mm}^{3}$ (as a disease control).

2) Group II (thrombocytopenic group): included 200 chronic HCV patients with platelets count between $30,000-149,000 / \mathrm{mm}^{3}$, further subdivided according to severity of thrombocytopenia into:

a) Group IIA (mild thrombocytopenia): included 80 chronic HCV patients with platelets count between $100,000-149,000 / \mathrm{mm}^{3}$.

b) Group IIB (moderate thrombocytopenia): included 120 chronic $\mathrm{HCV}$ patients with platelets count between $30,000-99,000 / \mathrm{mm}^{3}$.

The ethical committee of Faculty of Medicine at Zagazig University approved our study protocol and informed consent was obtained from all subjects at recruitment according to Helsinki declaration. Possible adverse effects of the antiviral therapy were explained to all subjects of the study.

Inclusion criteria for Dual treatment (sofosbuvir plus ribavirin for 6 months) according to national committee for chronic viral hepatitis (NCCVH), 2014 (interferon ineligibility):

- Males and females $\geq 18$ years.

- Child Score 5-7.

- Total bilirubin $\leq 5 \mathrm{mg} / \mathrm{dl}$.

- Albumin $\geq 2.5 \mathrm{gm} / \mathrm{dl}$.

- Platelet count $>30 \times 10^{3} / \mathrm{L}$.

- Hemoglobin Concentration $\geq 10 \mathrm{~g} / \mathrm{dl}$.

- Fibro scan $>8 \mathrm{k}$ Pascal or FIB4 test $\geq 2.5$.

- Creatinine $<2.5 \mathrm{mg} / \mathrm{dl}$ and Creatinine clearance $>30 \%$.

- Detectable HCV viremia by PCR.

- $\mathrm{HbA} 1 \mathrm{C}<8 \%$ for diabetic patients.

- Alpha fetoprotein (AFP) $<100 \mathrm{ng} / \mathrm{ml}$. Triphasic CT for exclusion of HCC if AFP > $100 \mathrm{ng} / \mathrm{ml}$.

- Female patient practicing contraception.

- Wife of male patient practicing contraception.

Inclusion criteria for Triple treatment (interferon plus ribavirin plus sofosbuvir for 3 months) according to NCCVH, 2014 (interferon eligibility):

- Age 18- 60 years old.

- Total bilirubin $\leq 1.2 \mathrm{mg} / \mathrm{dl}$.

- Serum albumin $\geq 3.5 \mathrm{~g} / \mathrm{dl}$.

- $\mathrm{INR} \leq 1.2$.

- Hemoglobin concentration $\geq 13 \mathrm{~g} / \mathrm{dl}$ for males and $\geq$ $12 \mathrm{~g} / \mathrm{dl}$ for females.

- Total leucocytic count $\geq 4000 / \mathrm{mm}^{3}$.

- Absolute neutrophil count $\geq 1500 / \mathrm{mm}^{3}$.

- Platelets count $\geq 100.000 / \mathrm{mm}^{3}$.

- $\mathrm{ANA} \leq 2$ folds.

- Absence of autoimmune and thyroid disease.

- Control of diabetes (HbA1C $\leq 8 \%)$.

- Absence of proliferative retinopathy.

- Absence of unstable cardiac disease.

- Non- organ transplant cases.

- Absence of unstable neuropsychiatric disorders.

- Absence of history of interferon intolerability.

- Absence of esophageal or gastric varices.
Exclusion criteria for treatment according to NCCVH, 2014:

- Patients with Child's score $\geq 8$.

- The presence or history of ascites.

- The presence or history of hepatic encephalopathy.

- Patients with hepatocellular carcinoma except after 3 months of successful radical curative intervention.

- Patients with risky esophageal varices except after prophylactic management.

- Cases of liver disease other than HCV.

- Hypersensitivity to interferon or ribavirn.

- Pregnancy or lactating female.

- Creatinine $>2.5 \mathrm{mg} / \mathrm{dl}$ or creatinine clearance $<30 \%$.

The severity of liver cirrhosis was scored according to Child's score.

\section{Methods}

All subjects underwent complete history taking (including history of hepatic encephalopathy, ascites, previous HCV treatment, previous endoscopies or upper GIT bleeding, diabetes, hypertension, smoking and contraceptive pills usage) and through physical examination.

\section{Routine Biochemical measurements}

As serum total and direct bilirubin, albumin , serum alanine transaminase (ALT) level, aspartate transaminase (AST), urea, creatinine, $\mathrm{CBC}$, Prothrombin time (PT), Prothrombin concentration, Partial thromboplastin time (PTT), International Normalizing Ratio (INR), TSH, ANA, Fasting, postprandial blood sugar, HA1c, AFP, HBs antigen, PCR for $\mathrm{HCV}$ RNA and pregnancy test. All patients were also subjected to fundus examination and cardiac evaluation.

\section{Radiological investigations}

Pelvi-abdominal ultrasonography: for examination of the liver, portal vein diameter, spleen, hilar varices, focal lesions and detection of ascitis.

Triphasic CT for patients with focal lesions or AFP $>100$ to exclude hepatocellular carcinoma.

\section{Staging of liver fibrosis according to}

METAVIR Score [12] or FIB-4 [13] or Transient elastography scoring (Fibro scan) [14].

N.B. Patients with FIB4 test $\geq 2.5$ were included.

Upper GIT endoscopy In F4 patients or fibroscan $\geq 19 \mathrm{~kb}$ for detection of varices.

\section{Treatment protocols:}

Triple therapy for 3 month: (in interferon eligible subjects) Sofosbuvir $400 \mathrm{mg}$ once daily + Pegylated interferon alfa-2a;180 mcg weekly or Pegylated interferon alfa-2b;1.5 mcg per kg weekly + ribavirin (RBV) $1200 \mathrm{mg}$ daily if weight $>75 \mathrm{~kg}$ or $1000 \mathrm{mg}$ daily if weight $\leq 75 \mathrm{~kg}$.

Dual therapy for 6 month: (in interferon ineligible subjects) Sofosbuvir 400mg once daily + ribavirin (RBV) $1200 \mathrm{mg}$ daily if weight $>75 \mathrm{~kg}$ or $1000 \mathrm{mg}$ daily if weight $\leq 75 \mathrm{~kg}$.

Follow- up: 


\section{International Journal of Science and Research (IJSR) \\ ISSN (Online): 2319-7064}

Index Copernicus Value (2015): 78.96 | Impact Factor (2015): 6.391

- Quantitative PCR at weeks 4, 12 and 24 (for triple therapy) and at weeks 4, 12, 24 and 36 (for dual therapy).

- ALT, AST, bilirubin at weeks 2, 4, 8,12,16,20 and 24.

- TSH at weeks 12 and 24 for triple therapy.

- $\mathrm{CBC}$ at weeks 2,4,8,12,16, 20 and 24.

- Kidney function tests at weeks 4, 8,12,16,20 and 24.

Stoppage of treatment was done on the occurrence of severe adverse effects as severe anemia and jaundice or new liver decompensation.

\section{Statistical analysis}

The obtained data were analyzed statistically using SPSS program version 20. Data were expressed as means \pm standard deviation in quantitative variables; and numbers and percentages for qualitative variables. IndependentSample (T), paired T test, (ANOVA), Chi-Square tests $\left(\mathrm{X}^{2}\right)$ were used when appropriate. The results were considered statistically significant if the $\mathrm{P}$ value was $<0.05$.

\section{Results}

\section{Basic characteristics of study groups}

Our subjects were matched as regards age, sex, and body mass index. The groups were also matched as regards some co morbid factors as diabetes mellitus (DM), hypertension, and smoking (Table 1). This study included treatment naive more than treatment experienced patients with a statistically significant difference $(p=0.02)$, however despite study included more non cirrhotic and Child's class A subjects, this didn't reach a statistical significance $(p>0.05)$ (Table 1).

Fib-4 score was significantly higher in thrombocytopenic patients when compared to patients with normal platelets $(\mathrm{p}<0.001)$ (Table 1).

\section{Outcome of treatment of study groups}

Percentages of cases with thrombocytopenia response to treatment, SVR and relapse didn't differ significantly from patients with normal platelet count $(p>0.05)$ (figure 1). Also in this study we studied the outcome of patients subjected to dual therapy in all groups and found that cases number and percentages with thrombocytopenia response to dual therapy, SVR and relapse didn't differ significantly from patients with normal platelet count $(p>0.05)$ (figure 2).

Effects of demographic and comorbid factors on outcome of treatment in thrombocytopenic patients

Sex and co morbid factors as DM and smoking had no impact on outcome of treatment as regards relapse rate or SVR $(p>0.05)$ (table 2,3), however SVR was significantly higher in hypertensive patients compared to non hypertensive subjects $(p=0.03)$ in group IIB (table 3$)$

Child's class A patients had significantly higher SVR and lower relapse rates compared to Child's class B in group IIB $(p=0.001)$ (table 3) but despite SVR was higher in Child's class A in group IIA, this didn't reach a statistical significance $(p>0.05)$ (table 2).
Cirrhotic patients had lower SVR and higher relapse compared to non cirrhotic patients $(p=0.03)$ in group IIA and IIB (table 2, 3), however other factors as experienced versus naive individuals in group IIA and IIB had no significant impact on SVR rate in patient with thrombocytopenia $(p>0.05)$ and type of therapy protocol also has no impact on SVR in group IIA thrombocytopenic patients $(p>0.05)$ (table 2).

Impact of thrombocytopenia on complications during and following treatment

Frequency and percentage of cases had complications after treatment as haematemsis, melena, development of hepatic encephalopathy or development of ascites didn't differ significantly in patients with thrombocytopenia (group II) from patients with normal platelet count (group I) $(p>0.05)$ (table 4), also discontinuation of therapy was similar in all groups due to the same complications $(p>0.05)$ (figure 2$)$.

\section{Impact of treatment on thrombocytopenia}

Antiviral therapy had a significant effect on improvement of platelets count at the end of treatment in group IIA and IIB patients received dual therapy ( $p=0.01 \& 0.00$ respectively), however, platelets count didn't improved following termination of triple therapy in group IIA $(p>0.05)$ (table 5).

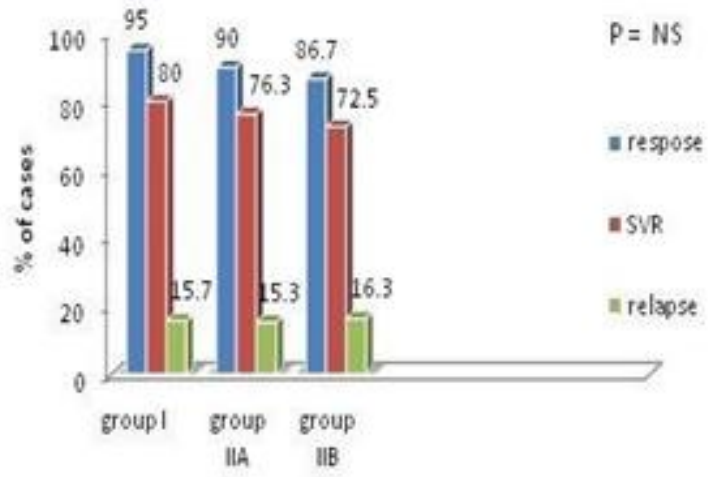

Study groups

Figure 1: Comparison between groups of study as regards percentages of end of treatment response, relapse rates and

SVR by Chi-Square: no significant difference between groups of study was found $(p=0.22,0.64,0.64$ respectively).

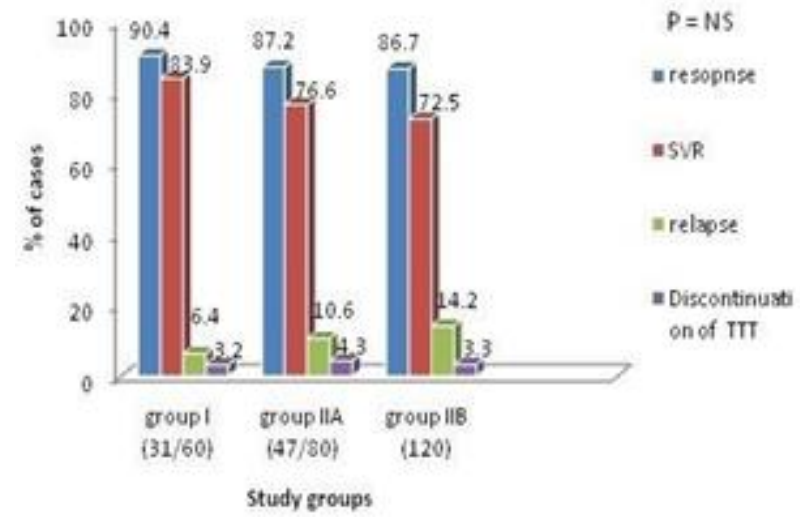

Figure 2: Comparison between individuals subjected to dual therapy in all groups as regards response, relapse, SVR, treatment discontinuation percentage of cases by Chi-Square 


\section{International Journal of Science and Research (IJSR) ISSN (Online): 2319-7064 \\ Index Copernicus Value (2015): 78.96 | Impact Factor (2015): 6.391}

: no significant difference was found $(p=0.22,0.08,0.44$, 0.44 respectively).

*Discontinuation of treatment occurred in one patient due to anemia $(\mathrm{HB} \%<8.5)$ despite reduced dose of ribavirin according to NCCVH, 2014 recommendations and erythropoietin therapy for at least 2 weeks, in 2 patients due to hyperbilirubinemia $>5 \mathrm{mg} / \mathrm{dl}$ and in one patient due to recurrent encephalopathy in group of thrombocytopenia.

Table 1: Basic characteristics of studied groups

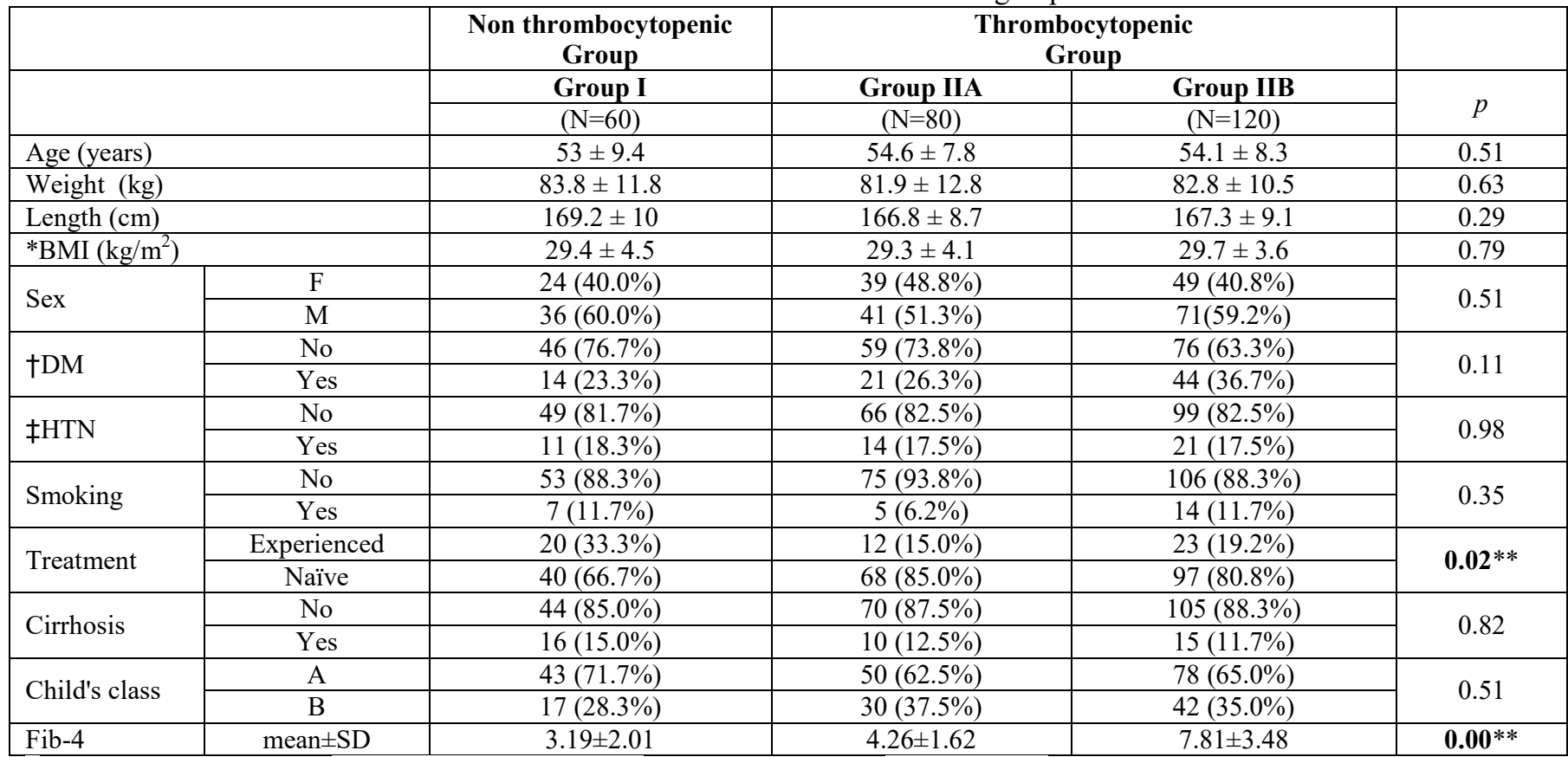

*BMI: body mass index; †DM: diabetes mellitus; $\ddagger$ HTN: hypertension; **: significant.

Table 2: Frequency and percentages of cases with SVR and relapse according to sex, comorbid factors, clinical characteristics and type of therapy protocol in group IIA (mild thrombocytopenia)

\begin{tabular}{|c|c|c|c|c|}
\hline & & $\begin{array}{c}\text { Relapse } \\
(n=11)\end{array}$ & $\begin{array}{c}\text { *SVR } \\
(n=61)\end{array}$ & $p$ \\
\hline \multirow{2}{*}{ Sex } & $\mathrm{F}$ & $5(14.7 \%)$ & $29(85.3 \%)$ & \multirow{2}{*}{0.89} \\
\hline & $\mathrm{M}$ & $6(15.8 \%)$ & $32(84.2 \%)$ & \\
\hline \multirow{2}{*}{$\mathrm{DM}$} & No & $9(16.4 \%)$ & $46(83.6 \%)$ & \multirow{2}{*}{0.64} \\
\hline & Yes & $2(11.8 \%)$ & $15(88.2 \%)$ & \\
\hline \multirow{2}{*}{ HTN } & No & $11(18.3 \%)$ & $49(81.7 \%)$ & \multirow{2}{*}{0.10} \\
\hline & Yes & $0(0 \%)$ & $12(100 \%)$ & \\
\hline \multirow{2}{*}{ Smoking } & No & $11(16.2 \%)$ & $57(83.8 \%)$ & \multirow{2}{*}{0.32} \\
\hline & Yes & $0(0 \%)$ & $4(100 \%)$ & \\
\hline \multirow{2}{*}{$\begin{array}{l}\text { Child's } \\
\text { class }\end{array}$} & $\mathrm{A}$ & $6(13 \%)$ & $40(87 \%)$ & \multirow{2}{*}{0.08} \\
\hline & B & $5(19.2 \%)$ & $21(80.8 \%)$ & \\
\hline \multirow{2}{*}{ †Cirrhosis } & No & $7(10.8 \%)$ & $5(89.2 \%)$ & \multirow[b]{2}{*}{0.03 ** } \\
\hline & Yes & $4(57.1 \%)$ & $3(42.9 \%)$ & \\
\hline \multirow{2}{*}{ Treatment } & Experienced & $2(20 \%)$ & $8(80 \%)$ & \multirow[b]{2}{*}{0.53} \\
\hline & Naïve & $9(14.5 \%)$ & $53(85.5 \%)$ & \\
\hline \multirow{2}{*}{$\begin{array}{l}\text { Therapy } \\
\text { Protocol }\end{array}$} & Dual & $5(12.2 \%)$ & $36(87.8 \%)$ & \multirow[b]{2}{*}{0.43} \\
\hline & Triple & $6(19.3 \%)$ & $25(80.6 \%)$ & \\
\hline
\end{tabular}

* SVR was evaluated by per-protocol analysis.

$†$ Cirrhosis defined as F3 or F4 on liver biopsy or $>12.5 \mathrm{~kb}$ on fibroscan.
Table 3: Frequency and percentages of cases with SVR and relapse according to sex, co morbid factors and clinical characteristics in group IIB (moderate thrombocytopenia)

\begin{tabular}{|c|c|c|c|c|}
\hline & & $\begin{array}{c}\text { Relapse } \\
(n=17)\end{array}$ & $\begin{array}{c}\text { SVR } \\
(n=87)\end{array}$ & $p$ \\
\hline \multirow{2}{*}{ Sex } & $\mathrm{F}$ & $6(14.3 \%)$ & $36(85.7 \%)$ & \multirow{2}{*}{0.64} \\
\hline & $\mathrm{M}$ & $11(17.7 \%)$ & $51(22.3 \%)$ & \\
\hline \multirow{2}{*}{ DM } & No & $12(17.7 \%)$ & $56(82.3 \%)$ & \multirow{2}{*}{0.62} \\
\hline & Yes & $5(13.9 \%)$ & $31(86.1 \%)$ & \\
\hline \multirow{2}{*}{ HTN } & No & $17(19.8 \%)$ & $69(80.2 \%)$ & \multirow{2}{*}{$\mathbf{0 . 0 3} * *$} \\
\hline & Yes & $0(0 \%)$ & $18(100 \%)$ & \\
\hline \multirow{2}{*}{ Smoking } & No & $15(16.1 \%)$ & $78(83.9 \%)$ & \multirow{2}{*}{0.82} \\
\hline & Yes & $21(8.2 \%)$ & $9(81.8 \%)$ & \\
\hline \multirow{2}{*}{$\begin{array}{l}\text { Child's } \\
\text { class }\end{array}$} & $\mathrm{A}$ & $10(14.5 \%)$ & $59(85.5)$ & \multirow{2}{*}{$0.001 * *$} \\
\hline & $\mathrm{B}$ & $7(20 \%)$ & $28(80 \%)$ & \\
\hline \multirow{2}{*}{ Cirrhosis } & No & $13(13.8 \%)$ & $81(86.2 \%)$ & \multirow[b]{2}{*}{$\mathbf{0 . 0 3} * *$} \\
\hline & Yes & $4(40 \%)$ & $6(60 \%)$ & \\
\hline \multirow{2}{*}{ Treatment } & Experienced & $15(26.3 \%)$ & $14(73.7 \%)$ & \multirow[b]{2}{*}{0.53} \\
\hline & Naïve & $12(14.2 \%)$ & $73(85.8 \%)$ & \\
\hline
\end{tabular}

Table 4: Frequency and percentages of cases developed complications after treatment in all groups.

\begin{tabular}{|l|c|c|c|c|}
\hline \multirow{2}{*}{ Complications } & Group I & Group IIA & Group IIB & \multirow{2}{*}{$P$} \\
\cline { 2 - 4 }$(\mathrm{N}=60)$ & $(\mathrm{N}=80)$ & $(\mathrm{N}=120)$ & \\
\hline Ascites (N=3) & $2(3.3 \%)$ & $0(0 \%)$ & $1(0.8 \%)$ & 0.13 \\
\hline $\begin{array}{l}\text { Encephalopathy } \\
(\mathrm{N}=4)\end{array}$ & $1(1.7 \%)$ & $2(2.5 \%)$ & $1(0.8 \%)$ & 0.56 \\
\hline $\begin{array}{l}\text { Hematemesis } \\
(\mathrm{N}=6)\end{array}$ & $1(1.7 \%)$ & $2(2.5 \%)$ & $3(2.5 \%)$ & 0.10 \\
\hline Melena $(\mathrm{N}=2)$ & $1(1.7 \%)$ & $0(0 \%)$ & $1(0.8 \%)$ & 0.32 \\
\hline
\end{tabular}




\section{International Journal of Science and Research (IJSR) \\ ISSN (Online): 2319-7064}

Index Copernicus Value (2015): 78.96 | Impact Factor (2015): 6.391

Table 5: Mean \pm SD of platelet Count before and after treatment in thrombocytopenic group

\begin{tabular}{|c|c|c|c|c|}
\hline \multicolumn{2}{|c|}{ Group } & $\begin{array}{c}\text { Before treatment } \\
\text { (Mean } \pm \text { SD) }\end{array}$ & $\begin{array}{c}\text { After treatment } \\
\text { (Mean } \pm \text { SD) }\end{array}$ & $p$ \\
\hline \multirow{2}{*}{ IIA } & Dual & $122.56 \pm 15.23$ & $135.52 \pm 32.6$ & $\mathbf{0 . 0 1} * *$ \\
\cline { 2 - 5 } & Triple & $128.4 \pm 13.7$ & $124.75 \pm 48.2$ & 0.42 \\
\hline IIB & Dual & $73.68 \pm 17.6$ & $106.58 \pm 2856$ & $\mathbf{0 . 0 0} * *$ \\
\hline
\end{tabular}

\section{Discussion}

Thrombocytopenia in chronic hepatitis $\mathrm{C}$ patients occurs due to the interaction of many factors. In general, these factors may be grouped into factors related to disease as hepatic fibrosis or cirrhosis, hypersplenism, bone marrow suppression, immune related and factors related to previous treatment by interferon therapy [9].

The greatest challenge in the care of chronic HCV patients with thrombocytopenia is the difficulty in initiating or maintaining anti-HCV therapy. In general, interferon-based antiviral therapy was contraindicated when platelet counts are below 75,000-100,000 cells/ $\mu \mathrm{L}[10]$.

Postponement of treatment due to thrombocytopenia can results in diminished sustained virological response because of the potential for further progression of liver disease in the absence of treatment; it may also heighten the need for additional therapies [11].

Previous treatment with pegylated interferon had been shown to reduce platelet counts by up to $33 \%$ therefore, even in patients with adequate platelet counts before therapy; platelet counts may decreases during therapy which could require a dose modification that may ultimately lower the chances of attaining sustained virological response [10].

In current study we found that in patients with thrombocytopenia, end of treatment response, sustained virological response (SVR) and relapse was not significantly differ from patients with normal platelet count as shown in figure $1 \& 2$ and this was not in agreement with Kanda et al [15] who observed that the response to treatment and SVR were lower in patients with thrombocytopenia and explained that by these patients were subjected to reduction of treatment doses. In interferon therapy, patients with platelet counts between $50,000 / \mathrm{mm}^{3}-80,000 / \mathrm{mm}^{3}$ should have a reduced dose and discontinuation if platelet counts fall below $25,000-50,000 / \mathrm{mm}^{3}[10]$.

We can explain our finding by that most of thrombocytopenic patients $(n=167 / 200)$ received dual therapy protocol and only 33 patients were subjected to interferon therapy for 12 week only versus 48 week for traditional previous interferon course and patients received dual therapy had a significant increase in platelet count following treatment (table 5) and were not subjected to dose reduction, however this was not in agreement with EASL 2015 reports that platelets less than $75,000 / \mathrm{mm}^{3}$ are negative predictor of response to treatment.

In assessment of the relationship of certain factors to relapse and SVR in patients with thrombocytopenia, we found that male gender didn't significantly differ from female gender and this was in agreement with Sezaki et al [16] who reported that the difference in response to treatment in chronic HCV according to sex is controversial.

D.M if controlled had no significant impact on SVR and relapse in patients with thrombocytopenia and this was consistent with El-Shazly, et al [17] who declared that well control diabetic patients had not decreased (SVR12). The patients included in our study had good control of diabetes before starting antiviral therapy $(\mathrm{HbA} 1 \mathrm{C}$ was $<8$ ), other patients with $\mathrm{HbA} 1 \mathrm{C}>8$ were in exclusion criteria.

El-Zayadi et al [18] reported in their study that smoking decreased response to treatment and decreased sustained virological response and explained that by patients with chronic HCV have lower levels of hepatic, plasma and lymphocytic glutathione that favor the hepatotoxic effect of smoking and reduce efficacy of treatment, but current study couldn't conclude these results.

Hypertensive patients had a statistically significant SVR and lower relapse rates compared to non hypertensive patients in group of patients with moderate thrombocytopenia (IIB) and this may be attributed to a smaller number of hypertensive individuals included in this study compared to non hypertensive subjects.

SVR was significantly higher in non - cirrhotic patients compared to cirrhotic patients and this was near to the results of Doss et al [19] who found that SVR rates in noncirrhotic patients $(93 \%)$ were higher than cirrhotic patients (78\%) following 12 weeks of treatment with sofosbuvir plus ribavirin. Also severity of liver disease evaluated by Child's score significantly affected sustained virological response in group IIB as patients with Child's class A had higher sustained virological response than Child's class B patients and this was consistent with the results of the study done by Afdhal et al [20] on 50 patients (Child's class A \& B) who received sofosbuvir and ribavirin for 48 weeks. Local fibrotic changes and intrahepatic shunting lead to an inadequate drug delivery, uptake, metabolism and viral clearance may be impaired as a result of immune defects caused by liver cirrhosis [21].

Despite that SVR was higher in treatment- naïve patients than treatment-experienced $(85.5 \%$ vs. 80$)$ and $(85.8 \%$ vs.73.7\%) in both groups IIA and IIB respectively and this was near to the results of Esmat et al [3] in a randomized trial conducted on 103 Egyptian patients with HCV genotype 4 received sofosbuvir and ribavirin for either 12 or 24 weeks. SVR rates were higher in treatment naïve $(92 \%$ in 24 -week treatment) than treatment experienced $(89 \%$ in $24-$ week treatment), but this didn't reach a statistical significance.

Percentages of cases with complications occurred during dual therapy as hyperbilirubinemia, anemia and recurrent encephalopathy that lead to discontinuation of treatment didn't significantly differ from patients with normal platelets as shown figure 2, also complications that occurred following the course of therapy didn't significantly differ between groups (table 4). Dyson et al [22] reported serious drug- induced hepatotoxicity with new directly acting 


\section{International Journal of Science and Research (IJSR) \\ ISSN (Online): 2319-7064}

Index Copernicus Value (2015): 78.96 | Impact Factor (2015): 6.391

antivirals (DAAs) with advanced liver disease and that the deterioration in liver functions may be due to co-morbidities in these patients or unknown interaction or reaction to drug combination but not due to thrombocytopenia.

In current study, no patients stopped treatment due to marked reduction in platelet count; Pockros et al [23] reported that some reactive thrombocytosis may occur secondary to ribavirin-induced hemolytic anemia.

Also antiviral therapy had significantly improved platelet count in patients subjected to dual therapy protocol in both group IIA and IIB and this was consistent with Danish et al [24] who declared that eradication of HCV infection results in remission of thrombocytopenia and also García et al [25] who reported that the reduction of HCV viremia following treatment correlated with significant improvement in platelet counts in the absence of hypersplenism or platelet autoantibodies. However platelet count wasn't increased after triple therapy protocol in group IIA, probably due to adverse effects of interferon on platelets count, the small number of patients with thrombocytopenia subjected to this therapy or that patient's platelets were not followed for a longer time.

\section{Conclusion and Future Scope}

We can conclude that thrombocytopenia had no impact on decreasing sustained virological response or increasing relapse with these sofosbuvir containing regimens used, dual therapy gave a chance to patients who are interferon ineligible to have treatment of their HCV with near good results when compared with triple therapy protocol. Cirrhosis and advanced Child's score are important factors in decreasing the rate of SVR in thrombocytopenic patients. The complications of therapy during and after antiviral course were the same as other patients with normal platelets count.

More future studies for evaluation of the efficacy and adverse effects of newly available directly acting antivirals in patients with thrombocytopenia especially for cirrhotic and treatment experienced patients are needed.

\section{Acknowledgments}

We would like to thank Clinical Pathology and Radiology staff in Zagazig University hospitals and El-Ahrar specialized centre for their help and all our patients who agree to enter our study for their generous assistance to complete this work.

\section{Conflict of interest}

None

\section{References}

[1] Ly KN, Xing J, Klevens RM, Jiles RB, Ward JW, Holmberg SD. The increasing burden of mortality from viral hepatitis in the United States between 1999 and 2007. Ann Intern Med. 2012; 156 (11): 271-278. Doi:
10.7326/0003-4819-156-4-201202210-00004; pubmed PMID: 22351712.

[2] Daw MA, Dau AA. Hepatitis C virus in Arab world: a state of concern. Scientific World Journal. 2012; 719494. Doi: 10.1100/2012/719494. Epub 2012 May 2; pubmed PMID: 22629189 ; pubmed central PMCID: PMC3354686.

[3] Esmat G. Hepatitis C in the Eastern Mediterranean Region. East Mediterr Health J. 2013; 19 (7):587-8. Pubmed PMID: 24975301.

[4] WHO 2015, media centre available from (www.emro.who.int).

[5] Seeff LB. Natural history of chronic hepatitis C. Hepatology. 2002; 36: S35-S46. Doi: 10.1053/jhep.2002.36806; pubmed PMID: 12407575.

[6] Ascione A, De Luca M, Tartaglione MT, et al. Peginterferon alfa-2a plus ribavirin is more effective than peginterferon alfa-2b plus ribavirin for treating chronic hepatitis $\mathrm{C}$ virus infection. Gastroenterology. 2010; 138(1):116-22. Doi: 10.1053/j.gastro.2009.10.005. Epub 2009 Oct 20; pubmed PMID: 19852964.

[7] Bhatia HK, Singh H, Grewal N, Natt NK. Sofosbuvir: A novel treatment option for chronic hepatitis C infection. J Pharmacol Pharmacother. 2014; 5(4):27884.doi: 10.4103/0976-500X.142464.

[8] Abdel-Razek W, Waked I. Optimal therapy in genotype 4 chronic hepatitis C: finally cured? Liver Int. 2015; 35(1): 27-34. Doi: 10.1111/liv.12724; pubmed PMID: 25529085.

[9] Giannini EG. Thrombocytopenia in chronic liver disease and pharmacologic treatment options. Aliment Pharmacol Ther. 2002; 23:1055-65; Dio: 10.1111/j.1365-2036.2006.02889.x; pubmed PMID 16611265.

[10]Dienstag JL and McHutchison JG. American Gastroenterological Association medical position statement on the management of hepatitis C. Gastroenterology. 2006; 130:225-30. Dio: 10.1053/j.gastro.2005.11.011; pubmed PMID: 16401485 .

[11] Afdhal N, McHutchison J, Brown R, et al. Thrombocytopenia associated with chronic liver disease. J Hepatol. 2008; 48:1000-7. Doi: 10.1016/j.jhep.2008.03.009. Epub 2008 Mar 31; pubmed PMID: 18433919.

[12]Rosen HR. Clinical practice. Chronic hepatitis C infection. N Engl J Med. 2011; 364(25):2429-38. Doi: 10.1056/NEJMcp1006613; pubmed PMID: 21696309.

[13] Vallet-Pichard A, Mallet V, Nalpas B, etal. FIB-4: an inexpensive and accurate marker of fibrosis in $\mathrm{HCV}$ infection. Comparison with liver biopsy and fibrotest. Hepatology. 2007; 46(1):32-6. Dio: 10.1002/hep.21669; pubmed PMID: 17567829 .

[14] Friedrich-Rust, Ong MF, Martens S ,et al. Performance of transient elastography for the staging of liver fibrosis: a meta-analysis. Gastroenterology. 2008; 134:960-74. Doi: 10.1053/j.gastro.2008.01.034. Epub 2008 Jan 18; pubmed PMID: 18395077.

[15] Kanda T, Kato K, Tsubota A, et al. Platelet count and sustained virological response in hepatitis $\mathrm{C}$ treatment. World J Hepatol. 2013; 5(4):182-8. Doi:

\section{Volume 6 Issue 1, January 2017




\section{International Journal of Science and Research (IJSR) \\ ISSN (Online): 2319-7064 \\ Index Copernicus Value (2015): 78.96 | Impact Factor (2015): 6.391}

10.4254/wjh.v5.i4.182; pubmed PMID:

23671722 PMCID; pubmed central PMC3648649.

[16] Sezaki H, Suzuk F, Kawamura Y, et al. Poor response to pegylated interferon and ribavirin in older women infected with hepatitis $\mathrm{C}$ virus of genotype $1 \mathrm{~b}$ in high viral loads. Dig Dis Sci. 2009; 54:1317-1324. Doi: 10.1007/s10620-008-0500-y. Epub 2008 Oct 28; pubmed PMID: 18958621.

[17] El-Shazly Y, Rafeek M and Al-Swaff R. Effect of wellcontrolled diabetes mellitus on sustained virologic response in chronic HCV genotype 4 infected patients. Journal of Diabetology. 2012; 2:3.

[18]El-Zayadi A, Selim Osaima, Hamdy H, et al. Impact of cigarette smoking on response to interferon therapy in chronic hepatitis C Egyptian patients. World J Gastroenterology. 2004; 10(20):2963-2966.pubmed PMID: 15378774; pubmed central PMCID: PMC4576253.

[19] Doss W, Shiha G, Hassany M, et al. Sofosbuvir plus ribavirin for treating Egyptian patients with hepatitis $\mathrm{C}$ genotype 4. J Hepatol. 2015; 63(3):581-5. Doi: 10.1016/j.jhep.2015.04.023. Epub 2015 May 1; PMID: 25937436.

[20] Afdhal N, Everson G.T, Calleja J.L, et al. Effect of long-term viral suppression with sofosbuvir + ribavirin on hepatic venous pressure gradient in $\mathrm{HCV}$-infected patients with cirrhosis and portal hypertension. In Proceedings of the EASL. 2015; Vienna, Austria.

[21] Saeed H. Al Marzooqi and Jordan J. Feld. Sorting out cirrhosis: Mechanisms of non-response to hepatitis C therapy. Liver International. 2015; 35(8):1923-1933. Doi: 10.1111/liv.12861. Epub 2015 Jun 3; pubmed PMID: 25939775.

[22] Dyson JK, Hutchinson J, Harrison L , et al. Liver toxicity associated with sofosbuvir, an NS5A inhibitor and ribavirin use. J Hepatol. 2016; 64(1):234-8. Doi: 10.1016/j.jhep.2015.07.041. Epub 2015 Aug 29; pubmed PMID: 26325535.

[23] Pockros PJ, Duchini A, McMillan R, et al. Immune thrombocytopenic purpura in patients with chronic hepatitis C virus infection. Am J Gastroenterol. 2002; 97:2040-5. Dio: 10.1111/j.1572-0241.2002.05845.x; Pubmed PMID: 12190174.

[24] Danish FA, Koul SS, Subhani FR, et al. Role of hematopoietic growth factors as adjuncts in the treatment of chronic hepatitis C patients. Saudi J Gastroenterol. 2008; 14:1. Doi:10.4103/13193767.41739; pubmed PMID: 19568529; pubmed central PMCID: PMC2702921.

[25] García-Suárez J, Burgaleta C, Hernanz N, et al. HCVassociated thrombocytopenia: clinical characteristics and platelet response after recombinant alpha2binterferon therapy. $\mathrm{Br} \mathrm{J}$ Haematol. 2000; 110:98-103. Pubmed PMID: 10930984. 